\title{
Preparation and Exceptional Lithium Anodic Performance of Porous Carbon-Coated ZnO Quantum Dots Derived from a Metal-Organic Framework
}

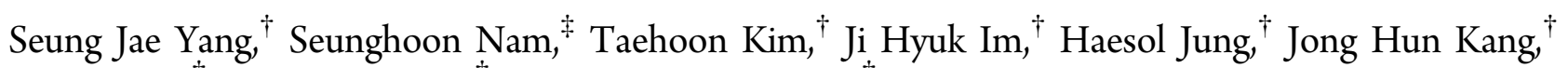
Sungun $\mathrm{Wi}^{\ddagger}$, Byungwoo Park, ${ }^{\ddagger}$ and Chong Rae Park ${ }^{*} \dagger$

${ }^{\dagger}$ Carbon Nanomaterials Design Laboratory, Global Research Laboratory, Research Institute of Advanced Materials, and Department of Materials Science and Engineering, Seoul National University, Seoul 151-744, Korea

${ }^{\ddagger}$ WCU Hybrid Materials Program, Department of Materials Science and Engineering, Research Institute of Advanced Materials, Seoul National University, Seoul 151-744, Korea

\section{Supporting Information}

ABSTRACT: Hierarchically porous carbon-coated $\mathrm{ZnO}$ quantum dots (QDs) $(\sim 3.5 \mathrm{~nm})$ were synthesized by a one-step controlled pyrolysis of the metal-organic framework IRMOF-1. We have demonstrated a scalable and facile synthesis of carbon-coated $\mathrm{ZnO}$ QDs without agglomeration by structural reorganization. This unique microstructure exhibits outstanding electrochemical performance (capacity, cyclability, and rate capability) when evaluated as an anode material for lithium ion batteries.

T ithium ion batteries (LIBs), a fast-developing technology area in electric energy storage, are a promising power source for a wide range of portable electronic devices. ${ }^{1,2}$ A variety of materials may be used in LIBs. As an example, metal oxides can potentially be substituted for graphite $\left(\sim 370 \mathrm{~mA} \mathrm{~h} \mathrm{~g}{ }^{-1}\right)$ in current platforms to meet the demand for high capacities. ${ }^{1-3}$ Most metal oxides undergo an undesirable large volume change that leads to a dramatic falloff in capacity during cycling. Several methods have been developed to overcome this problem, including the fabrication of nanostructured electrodes, such as nanoparticles, nanowires, or nanotubes, or the preparation of hybrid composites with an inactive matrix, such as carbon, that mechanically buffers against volume changes. ${ }^{1-6}$

Metal-organic frameworks (MOFs) represent an emerging class of materials that have attracted extensive research interest because of their tunable porosities and versatile functionalities. ${ }^{7}$ Numerous applications have been investigated, including gas storage and separation, catalysis, sensing, and gas chromatography. ${ }^{8-10}$ In recent years, several theoretical and experimental approaches have indicated that some MOFs behave as semiconductors in metal oxide quantum dot (QD) configurations. $^{11}$ Such MOFs exhibit photocatalytic activities and photoluminescence $(\mathrm{PL})$ that result from their hybrid structures involving periodically dispersed metal oxide clusters separated by organic spacers. The properties of the hybrid structures have motivated the development of facile preparations of welldispersed metal oxide QDs embedded in porous carbon matrices comprising MOFs (Figure 1) as well as studies of anode LIB materials with minimal volume changes during cycling.

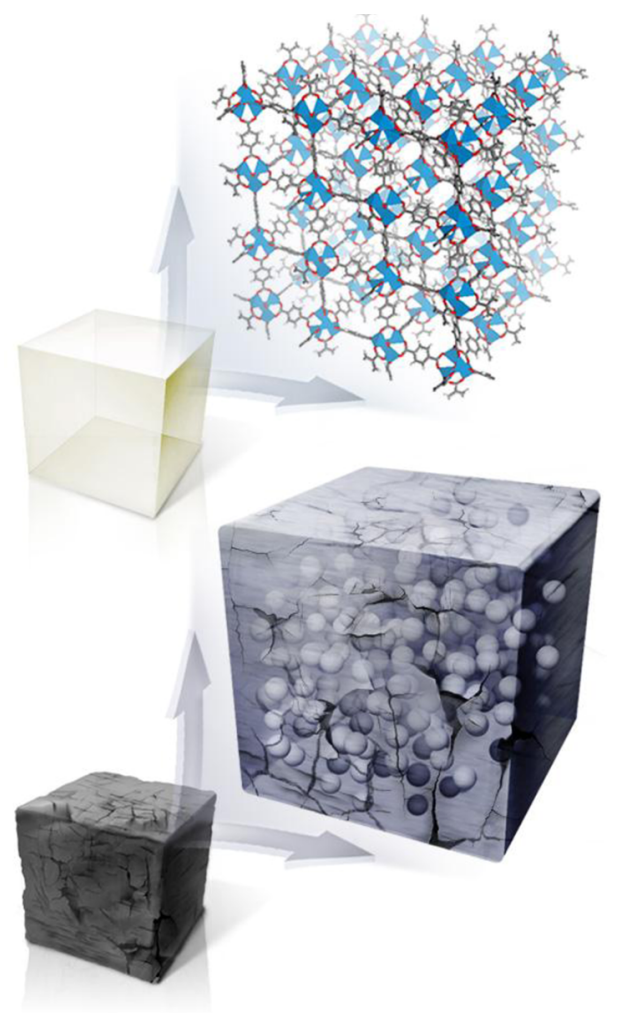

Figure 1. Schematic diagrams of IRMOF-1 (top) and IRMOF-1 after controlled pyrolysis to produce carbon-coated $\mathrm{ZnO}$ QDs without agglomeration (bottom). The $\mathrm{ZnO}$ QDs are covered with a thin amorphous carbon layer that acts as a buffer layer to confine the QDs during the charging and discharging steps.

In this work, we examined isoreticular MOF-1 (IRMOF-1, conventionally denoted as MOF-5; Figure S1 in the Supporting Information) as a case study because it is amenable to mass production, it has high crystallinity, and its purity can be excellent. ${ }^{12}$ Although preparations of porous $\mathrm{Fe}_{2} \mathrm{O}_{3}$ bulk materials from $\mathrm{Fe}$-based MOFs ${ }^{13,14}$ have recently been reported,

Received: November 26, 2012

Published: May 7, 2013 
those studies focused only on the metallic product after removal of the organic constituent of the MOF. Unlike the previous reports, we have developed a novel and facile approach to the synthesis of zinc oxide $(\mathrm{ZnO})$ QDs $(\sim 3.5 \mathrm{~nm})$ without intrinsic defects or agglomeration embedded in hierarchically porous carbon matrices derived from IRMOF-1. The tailor-fit microstructures enabled the display of exceptionally high Li storage performances. Thus, the proposed method provides new effective ways to fabricate high-performance anode materials based on a metal oxide@porous carbon matrix.

The structural reorganization of the MOF to $\mathrm{ZnO}$ QDs@ porous carbon, synthesized via a controlled pyrolysis reaction to obtain the initial state of the transformation (Figure S2), was investigated by scanning electron microscopy (SEM) and transmission electron microscopy (TEM). The samples are designated by the heat treatment temperature (in ${ }^{\circ} \mathrm{C}$ ) followed by the atmospheric conditions (e.g., "550N" denotes a sample heated at $550{ }^{\circ} \mathrm{C}$ under an inert atmosphere). SEM micrographs (Figure $2 \mathrm{a}, \mathrm{b}$ ) indicated that $550 \mathrm{~N}$ retained the pristine cubic

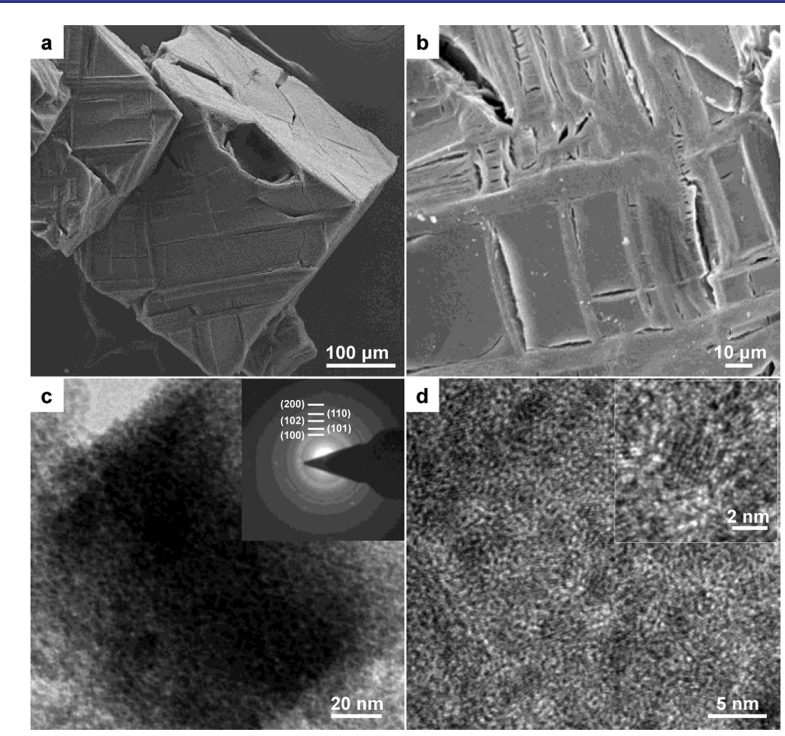

Figure 2. ZnO QDs@porous carbon (550N) obtained from IRMOF-1: (a, b) SEM images; (c) TEM image (inset: SAED pattern); (d) highresolution TEM image (inset: enlarged view).

morphology of the as-prepared IRMOF-1 even after hightemperature heating. ${ }^{15,16}$ Black microparticles were observed (Figure S3), with cracked surfaces that developed during decomposition of the organic species. ${ }^{12,16}$ TEM images revealed that the cubic microparticles consisted of $\mathrm{ZnO} \mathrm{QDs}$ and amorphous carbon. The selected-area electron diffraction (SAED) pattern (Figure $2 \mathrm{c}$ inset) displayed a typical hexagonal wurtzite crystal structure of $\mathrm{ZnO}$, indicating that the carbon obtained was nearly amorphous and lacked long-range order. Figures $2 \mathrm{~d}$ and S4 clearly confirmed that the highly crystalline $\mathrm{ZnO}$ QDs were well-dispersed, not agglomerated, and nearly monodisperse, with a mean particle size of $3 \pm 1 \mathrm{~nm}$ in the amorphous carbon matrix.

Figure 3a presents an X-ray diffraction (XRD) pattern for $550 \mathrm{~N}$ with Bragg peaks corresponding to $\mathrm{ZnO}$, consistent with the SAED patterns. The corresponding $\mathrm{ZnO}$ peaks exhibited line broadening due to the small size of the obtained $\mathrm{ZnO}$ particles. The measured size of the $\mathrm{ZnO}$ particles as determined using the Scherrer formula (Figure S5) was approximately $3.5 \mathrm{~nm}$, in good agreement with the TEM results. ${ }^{17}$ PL spectroscopy was used to
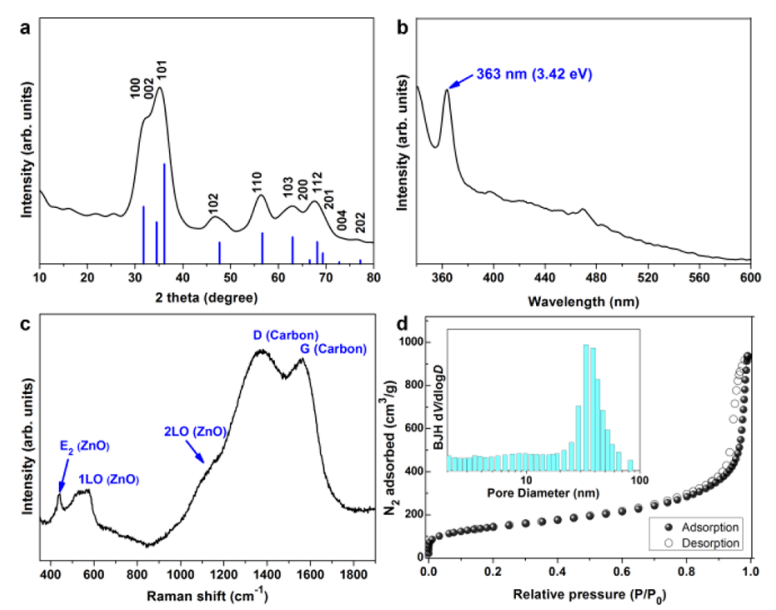

Figure 3. (a) XRD pattern, (b) PL spectrum, (c) Raman spectrum, and (d) nitrogen adsorption isotherm at $77 \mathrm{~K}$ for the $550 \mathrm{~N}$ sample. The inset in (d) is the pore size distribution calculated using the BJH equation.

characterize the atomic defects and crystalline size of the $\mathrm{ZnO}$. In the PL spectrum (Figure 3b), the predominant PL emission peak occurred at $363 \mathrm{~nm}(3.42 \mathrm{eV})$. This peak is blue-shifted compared with the excitonic emission peak corresponding to a typical band gap of bulk $\mathrm{ZnO}(3.36 \mathrm{eV}) .{ }^{17,18}$ The shift in the emission peak was ascribed to a quantum-confinement-induced energy gap enhancement, further emphasizing the quantum size of the resultant $\mathrm{ZnO}$. Another notable feature of this spectrum is the lack of a low-energy blue-green emission band due to the surface defects associated with oxygen vacancies or interstitial zinc sites. ${ }^{16-18}$ Combined with the X-ray photoemission spectroscopy (XPS) analysis of 550N (Figure S6), this result indicated that the $\mathrm{ZnO}$ QDs were high in quality.

As revealed by TEM imaging, the Raman spectrum of the $550 \mathrm{~N}$ sample (Figure 3c) confirmed the coexistence of $\mathrm{ZnO}$ QDs and amorphous carbon. The $550 \mathrm{~N}$ sample displayed two distinct bands at 1320 and $1590 \mathrm{~cm}^{-1}$ assigned to the typical D and $\mathrm{G}$ bands of amorphous carbon, respectively, and three different bands associated with the $\mathrm{ZnO}$ QDs. ${ }^{16,18,19}$ The $\mathrm{E}_{2}$ phonon frequency occurs at $436 \mathrm{~cm}^{-1}$ for $\mathrm{ZnO}$ QDs with sizes of less than $10 \mathrm{~nm}$, which is red-shifted from $475 \mathrm{~cm}^{-1}$ for bulk $\mathrm{ZnO}$ particles. ${ }^{18}$ Combined with the $\mathrm{PL}$ and XRD results, the $\mathrm{E}_{2}$ band of $550 \mathrm{~N}$ strongly supported the formation of $\mathrm{ZnO}$ QDs. The textural characteristics of the product were quantified by measuring the nitrogen adsorption isotherm (Figure 3d) at 77 $\mathrm{K}$. The specific surface area (SSA) calculated using the Brunauer-Emmett-Teller (BET) equation and the total pore volume at $P / P_{0}=0.98$ were $513 \mathrm{~m}^{2} \mathrm{~g}^{-1}$ and $1.27 \mathrm{~cm}^{3} \mathrm{~g}^{-1}$, respectively. The pore size distribution calculated using the Barrett-Joyner-Halenda (BJH) equation (Figure 3d inset) revealed a mesoporosity of the resultant material centered at 35 $\mathrm{nm}$. Combined with the observation of a considerable increase of nitrogen adsorption at low pressure, this material exhibited a hierarchical pore system consisted of micro- and mesopores. In view of the quantity of amorphous carbon in the $550 \mathrm{~N}$ sample [ 32 wt \% as determined by thermogravimetric analysis (TGA); Figure S7], a BET SSA of $513 \mathrm{~m}^{2} \mathrm{~g}^{-1}$ is remarkably high compared with the values reported for metal oxide@porous carbon composites. ${ }^{3,6}$ This high SSA, coupled with the TEM, $\mathrm{XRD}, \mathrm{PL}$, and Raman results, was attributable to the formation of unagglomerated, quantum-sized $\mathrm{ZnO}$ and porous carbon hybrid particles. 

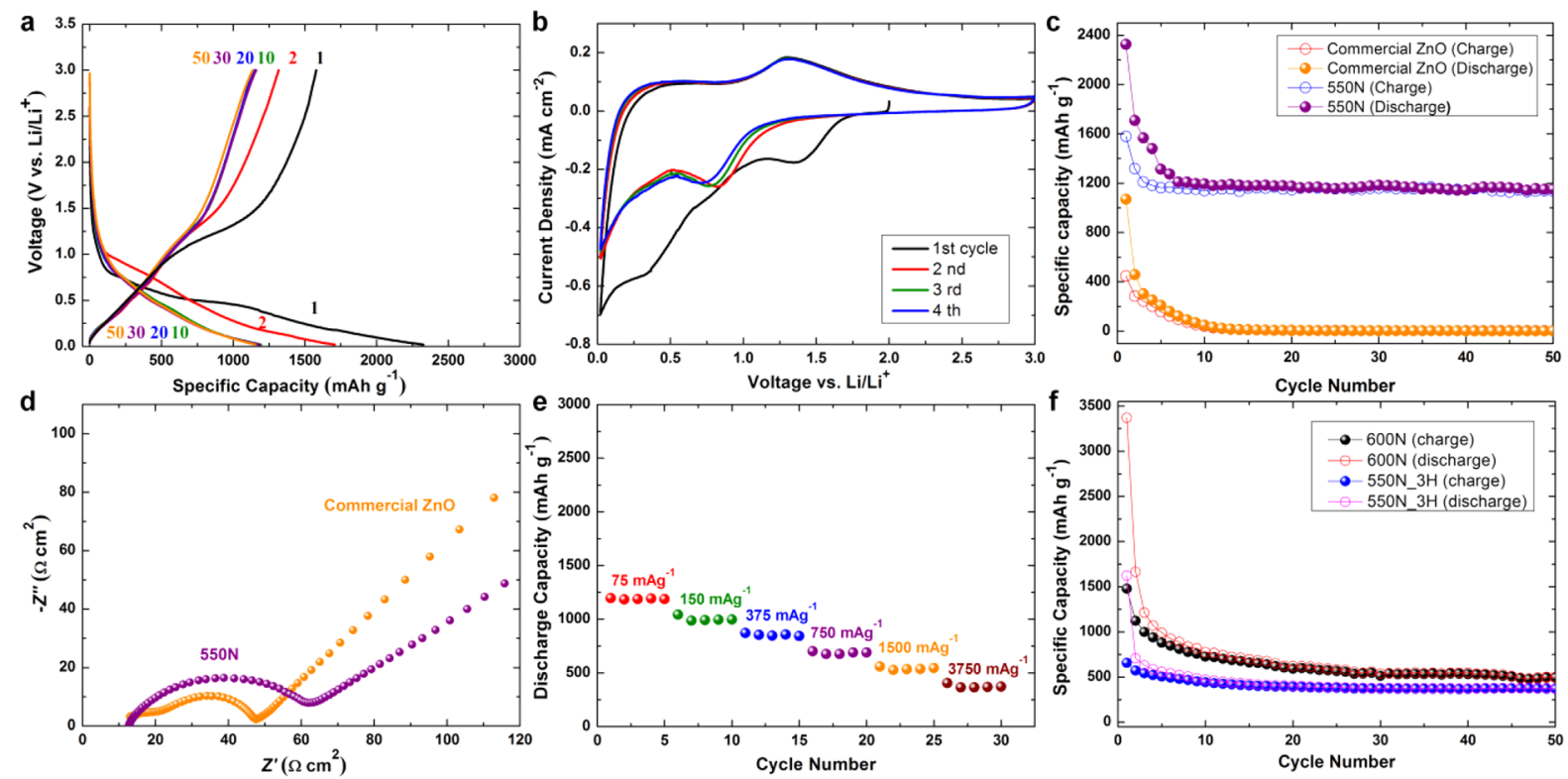

Figure 4. (a) Voltage profile of $550 \mathrm{~N}$. The cell was tested for 50 cycles between $20 \mathrm{mV}$ and $3.0 \mathrm{~V}$ under a current density of $75 \mathrm{~mA} \mathrm{~g}{ }^{-1}$. (b) Cyclic voltammetry measurements on $550 \mathrm{~N}$ during the first four cycles. The voltage range was $20 \mathrm{mV}$ to $3.0 \mathrm{~V}$ at a scan rate of $0.1 \mathrm{mV} \mathrm{s} \mathrm{s}^{-1}$. The initial point corresponded to the open-circuit voltage of the cell. (c) Cycle-life performances of $550 \mathrm{~N}$ and the commercial $\mathrm{ZnO}$ counterpart $\left(75 \mathrm{~mA} \mathrm{~g} \mathrm{~g}^{-1}\right)$. $(\mathrm{d})$ Nyquist plots for $550 \mathrm{~N}$ and the commercial $\mathrm{ZnO}$ powder after three cycles under an applied voltage of $0.256 \mathrm{~V}$. (e) Discharge capacity of $550 \mathrm{~N}$ at various current densities. The cells were cycled 20 times at a current density of $75 \mathrm{~mA} \mathrm{~g}^{-1}$ prior to variation of the current density from 75 to $3750 \mathrm{~mA}$ $\mathrm{g}^{-1}$. (f) Cycle-life performances of $600 \mathrm{~N}$ and $550 \mathrm{~N} \_3 \mathrm{H}$ at a current density of $75 \mathrm{~mA} \mathrm{~g}^{-1}$.

The formation of ZnO QDs@porous carbon was investigated in detail by carrying out the pyrolysis of MOFs under various conditions (Figures S8-S11). At high target temperatures, the QDs readily ripened, and the resultant particles were estimated to be $\sim 20 \mathrm{~nm}$ in size (XRD results) without a uniform shape (TEM image). Aside from the target temperature, the duration of heating at $550^{\circ} \mathrm{C}$ and the heating rate played important roles in the evolution of the nanostructures. Irregular ripening of the $\mathrm{ZnO}$ QDs occurred, as observed at higher target temperatures. The high surface energies of the very small particles may have accelerated the ripening, even under slightly different conditions. The pyrolysis conditions led to a reduction in $\mathrm{ZnO}$ while simultaneously inducing surface defects. The PL characteristics of the materials were consistent with the observation of a green emission band corresponding to $\mathrm{O}$ defects on the obtained $\mathrm{ZnO}$ crystals (Figure S12). 15,16,18,20

The galvanostatic charge/discharge curve for $550 \mathrm{~N}$ is presented in Figure 4a. The plateau in the first cycle indicated a three-phase equilibrium region in the $\mathrm{Zn}-\mathrm{Li}-\mathrm{O}$ system $\left(\mathrm{ZnO}-\mathrm{Li}_{2} \mathrm{O}-\mathrm{Zn}\right)$. The large initial capacity $\left(\sim 2300 \mathrm{~mA} \mathrm{~h} \mathrm{~g}{ }^{-1}\right)$ can be understood on the basis of the reduction of $\mathrm{ZnO}$ to give $\mathrm{Zn}$ plus the formation of a solid-electrolyte interphase (SEI) layer on the surface of the ZnO QDs@porous carbon. These reactions were supported by the cyclic voltammetry measurements (Figure 4b), in which the first scan curve differed significantly from subsequent cycles. The initial capacity was lost in a continuous way during the first few cycles, after which the cycle-life performance of $550 \mathrm{~N}$ stabilized. The initial loss of capacity arose mainly from the incomplete conversion reaction and irreversible lithium loss due to the formation of the SEI layer. ${ }^{21}$ This leads to poor Coulombic efficiency, and such an irreversible capacity is deleterious to practical applications. Intensive work should be expended in the future to improve the first Coulombic efficiency. The capacity after the seventh cycle, however, tended to saturate with a discharge capacity of $1150 \mathrm{~mA}$ $\mathrm{h} \mathrm{g}^{-1}$. It should be noted that some of the reversible capacity $\left(\sim 107 \mathrm{~mA} \mathrm{~h} \mathrm{~g}^{-1}\right)$ originated from the Super P carbon black, considering that it stores lithium ion (Figure S13) and was $20 \mathrm{wt}$ $\%$ of the whole electrode. This performance far surpasses that of any other material based on $\mathrm{ZnO}{ }^{22}$ The cycle-life performance of $550 \mathrm{~N}$ is shown in Figure $4 \mathrm{c}$ along with that of commercial $\mathrm{ZnO}$ nanopowder (Aldrich; for its XRD and nitrogen adsorption isotherm, see Figure S14) measured for comparison purposes. The cells prepared with the commercial $\mathrm{ZnO}$ nanopowder died only after 10 cycles, as reported earlier. ${ }^{23}$ It should be noted that the capacity here is that of the $\mathrm{ZnO}$ QDs plus that of the amorphous carbon, and the $\mathrm{C}$ rate was calculated on the basis of the theoretical capacity considering the relative amounts of $\mathrm{ZnO}$ and amorphous carbon: $981(\mathrm{ZnO}) \times 0.68+470$ (amorphous carbon; Figure S15) $\times 0.32=817 \mathrm{~mA} \mathrm{~h} \mathrm{~g}^{-1}$ for $550 \mathrm{~N}$. The capacity of amorphous carbon only is displayed in Figure S15.

Interestingly, the measured capacity exceeded the theoretically predicted capacity, and the cyclability was exceptional compared with the reported values. ${ }^{22-24}$ The origin of the outstanding performance is that each $\mathrm{ZnO}$ QD was coated with amorphous carbon in the highly long-range-ordered structure of the MOF precursor. $^{7}$ Complete encapsulation of nanoparticles is not ensured in conventional amorphous carbon-coated $\mathrm{ZnO}$, whereas the framework yielded a relatively uniform well-defined coating layer. The carbon coating layer effectively prevented volume expansion during consecutive alloying-dealloying processes. The beneficial buffer effect was qualitatively measured using Nyquist plots for $550 \mathrm{~N}$ and the commercial $\mathrm{ZnO}$ nanopowder (Figure 4d). The impedance associated with the charge-transfer resistance in $550 \mathrm{~N}$ exceeded that of the commercial $\mathrm{ZnO}$ nanopowder. The amorphous carbon layer synthesized at a relatively low temperature $\left(550^{\circ} \mathrm{C}\right)$ may not have contributed significantly to the conductivity as a result of the insufficient thermal treatment and nongraphitizable precursor, leading us to conclude that the electrochemical 
performance of $\mathrm{ZnO}$ depended more on buffering of the volume expansion. ${ }^{25,26}$ The commercial $\mathrm{ZnO}$ nanopowder exhibited a circle in the Nyquist plot due to the SEI layer (Figure 4d), whereas $550 \mathrm{~N}$ exhibited only a single circle associated with the charge-transfer resistance. The amorphous carbon may have reduced the undesirable growth of the SEI layer. ${ }^{27}$ Consequently, the circle associated with the SEI layer in the Nyquist plot of $550 \mathrm{~N}$ was insignificant. Furthermore, the large surface area of such small-sized QDs $(\sim 3.5 \mathrm{~nm})$ might contribute to extra charge storage, which was found to be reversible during cycling, leading to a capacity exceeding $982 \mathrm{~mA} \mathrm{~h} \mathrm{~g}^{-1}\left(\mathrm{C}_{\text {theoretical }}\right.$ of $\mathrm{ZnO}){ }^{28}$ It is presumed that the surface of the $\mathrm{ZnO}$ QDs is greatly exposed to the $\mathrm{Li}^{+}$environment since each $\mathrm{QD}$ is separated by amorphous carbon. Therefore, several phenomena, such as interfacial charge storage via weakly bound $\mathrm{Li}$ at the surface of $\mathrm{ZnO}$ QDs, reactions with the electrolyte, and charge separation at the SEI layer could possibly occur, to which the extra capacity is attributed. ${ }^{29,30}$ On the contrary, the carbon-coated nanoparticles reported to date became more or less aggregated during battery cycling, and therefore, the contribution of capacity from alternative ways of $\mathrm{Li}$ storage seemed negligible. The $\mathrm{ZnO}$ QD size benefited the rate of $\mathrm{Li}$ ion diffusion, as reflected in the rate capability results (Figure 4e). The above discussion reveals that the $\mathrm{ZnO}$ particle size increased dramatically, and the particles included many internal defects, leading to poorer electrochemical properties than were observed in the $550 \mathrm{~N}$ sample. The cycle-life performances of the $600 \mathrm{~N}$ and $550 \mathrm{~N}$ _3H samples, both of which displayed large particle sizes, are illustrated in Figure $4 \mathrm{f}$. The higher initial irreversible capacity of $600 \mathrm{~N}$ compared with that of the $550 \mathrm{~N}$ might be due to the severe SEI formation on the surface of the porous carbon in $600 \mathrm{~N}^{31-33}$ Both the crystal size and perfectness of the $\mathrm{ZnO}$ particles made important contributions to the enhanced electrochemical performance.

In summary, a controlled pyrolysis of MOFs for the synthesis of porous carbon-coated $\mathrm{ZnO}$ QDs without agglomeration has been demonstrated. The materials exhibited promising Li storage properties and high specific charge capacities $\left(\sim 1200 \mathrm{~mA} \mathrm{~h} \mathrm{~g}^{-1}\right.$ at $\left.75 \mathrm{~mA} \mathrm{~g}^{-1}\right)$. The capacity was estimated on the basis of the total composite weight, the stable cyclability $(\sim 50$ cycles with nearly $100 \%$ capacity retention), and the good performance rate $(\sim 400$ $\mathrm{mA} \mathrm{h} \mathrm{g}^{-1}$ at $3750 \mathrm{~mA} \mathrm{~g}^{-1}$ ). The very first Coulombic efficiency that arises from the high initial discharge capacity is significantly low, and this should be resolved in the future from a practical point of view. Nonetheless, the novel and facile synthesis introduced here provides insight into the $\mathrm{ZnO}$ system, which has not been extensively examined to date for use as an LIB anode. This concept may potentially be expanded to other high-capacity metal oxide anode material systems that undergo a large volume expansion during an electrochemical reaction.

\section{ASSOCIATED CONTENT}

\section{S Supporting Information}

Experimental section and additional data. This material is available free of charge via the Internet at http://pubs.acs.org.

\section{AUTHOR INFORMATION}

\section{Corresponding Author}

crpark@snu.ac.kr

\section{Notes}

The authors declare no competing financial interest.

\section{ACKNOWLEDGMENTS}

This work was supported by National Research Foundation of Korea (NRF) Grants funded by the Korean Government (MEST) (2010-0029244 and 2012-0000580).

\section{REFERENCES}

(1) Bruce, P. G.; Scrosati, B.; Tarascon, J.-M. Angew. Chem., Int. Ed. 2008, 47, 2930.

(2) Scrosati, B.; Hassoun, J.; Sun, Y.-K. Energy Environ. Sci. 2011, 4, 3287.

(3) Wu, Z.-S.; Zhou, G.; Yin, L.-C.; Ren, W.; Li, F.; Cheng, H.-M. Nano Energy 2012, 1, 107.

(4) Myung, S.-T.; Takahashi, N.; Komaba, S.; Yoon, C. S.; Sun, Y.-K.; Amine, K.; Yashiro, H. Adv. Funct. Mater. 2011, 21, 3231.

(5) Lee, J.-I.; Lee, K. T.; Cho, J.; Kim, J.; Choi, N.-S.; Park, S. Angew. Chem., Int. Ed. 2012, 51, 2767.

(6) Lee, K. T.; Cho, J. Nano Today 2011, 6, 28.

(7) Farrusseng, D.; Aguado, S.; Pinel, C. Angew. Chem., Int. Ed. 2009, 48,7502 .

(8) Lee, C. Y.; Bae, Y.-S.; Jeong, N. C.; Farha, O. K.; Sarjeant, A. A.; Stern, C. L.; Nickias, P.; Snurr, R. Q.; Hupp, J. T.; Nguyen, S. T. J. Am. Chem. Soc. 2011, 133, 5228.

(9) Lan, Y.-Q.; Jiang, H.-L.; Li, S.-L.; Xu, Q. Adv. Mater. 2011, 23, 5015.

(10) Gu, Z.-Y.; Yan, X.-P. Angew. Chem., Int. Ed. 2010, 49, 1477.

(11) Bordiga, S.; Lamberti, C.; Ricchiardi, G.; Regli, L.; Bonino, F.; Damin, A.; Lillerud, K. P.; Bjorgen, M.; Zecchina, A. Chem. Commun. 2004, 2300 .

(12) Yang, S. J.; Park, C. R. Adv. Mater. 2012, 24, 4010.

(13) Zhang, L.; Wu, H. B.; Madhavi, S.; Hng, H. H.; Lou, X. W. J. Am. Chem. Soc. 2012, 134, 17388.

(14) Xu, X.; Cao, R.; Jeong, S.; Cho, J. Nano Lett. 2012, 12, 4988.

(15) Liu, B.; Shioyama, H.; Akita, T.; Xu, Q. J. Am. Chem. Soc. 2008, 130, 5390.

(16) Yang, S. J.; Kim, T.; Im, J. H.; Kim, Y. S.; Lee, K.; Jung, H.; Park, C. R. Chem. Mater. 2012, 24, 464.

(17) Feng, P. L.; Perry, J. J., IV; Nikodemski, S.; Jacobs, B. W.; Meek, S. T.; Allendorf, M. D. J. Am. Chem. Soc. 2010, 132, 15487.

(18) Son, D. I.; Kwon, B. W.; Park, D. H.; Seo, W.-S.; Yi, Y.; Angadi, B.; Lee, C.-L.; Choi, W. K. Nat. Nanotechnol. 2012, 7, 465.

(19) Hu, Y.-S.; Demir-Cakan, R.; Titirici, M.-M.; Müller, J.-O.; Schlögl, R.; Antonietti, M.; Maier, J. Angew. Chem., Int. Ed. 2008, 47, 1645.

(20) Vanheusden, K.; Warren, W. L.; Seager, C. H.; Tallant, D. R.; Voigt, J. A.; Gnade, B. E. J. Appl. Phys. 1996, 79, 7983.

(21) Wu, Z.-S.; Ren, W.; Wen, L.; Gao, L.; Zhao, J.; Chen, Z.; Zhou, G.; Li, F.; Cheng, H.-M. ACS Nano 2010, 4, 3187.

(22) Ahmad, M.; Yingying, S.; Nisar, A.; Sun, H.; Shen, W.; Wei, M.; Zhu, J. J. Mater. Chem. 2011, 21, 7723.

(23) Huang, X. H.; Xia, X. H.; Yuan, Y. F.; Zhou, F. Electrochim. Acta 2011, 56, 4960.

(24) Wang, H.; Pan, Q.; Cheng, Y.; Zhao, J.; Yin, G. Electrochim. Acta 2009, 54, 2851.

(25) Kushima, A.; Liu, X. H.; Zhu, G.; Wang, Z. L.; Huang, J. Y.; Li, J. Nano Lett. 2011, 11, 4535.

(26) Nam, S.; Kim, S.; Wi, S.; Choi, H.; Byun, S.; Choi, S.-M.; Yoo, S. I.; Lee, K. T.; Park, B. J. Power Sources 2012, 211, 154.

(27) Yoo, J.-K.; Kim, J.; Jung, Y. S.; Kang, K. Adv. Mater. 2012, 24, 5452.

(28) Qie, L.; Chen, W.-M.; Wang, Z.-H.; Shao, Q.-G.; Li, X.; Yuan, L.X.; Hu, X.-L.; Zhang, W.-X.; Huang, Y.-H. Adv. Mater. 2012, $24,2047$.

(29) Jamnik, J.; Maier, J. Phys. Chem. Chem. Phys. 2003, 5, 5215.

(30) Wu, Y.; Wei, Y.; Wang, J.; Jiang, K.; Fan, S. Nano Lett. 2013, 13, 818.

(31) Hu, Y. S.; Adelhelm, P.; Smarsly, B. M.; Hore, S.; Antonietti, M.; Maier, J. Adv. Funct. Mater. 2007, 17, 1873.

(32) Guo, B.; Wang, X.; Fulvio, P. F.; Chi, M.; Mahurin, S. M.; Sun, X.G.; Dai, S. Adv. Mater. 2011, 23, 4661.

(33) Fang, Y.; Lv, Y.; Che, R.; Wu, H.; Zhang, X.; Gu, D.; Zheng, G.; Zhao, D. J. Am. Chem. Soc. 2013, 135, 1524. 


\title{
Supporting Information
}

\author{
"Preparation and Exceptional Lithium Anodic Performance of Porous Carbon- \\ Coated ZnO Quantum Dots Derived from a Metal Organic Framework”
}

Seung Jae Yang, Seunghoon Nam, Taehoon Kim, Ji Hyuk Im, Haesol Jung, Jong Hun Kang, Sungun Wi, Byungwoo Park, and Chong Rae Park*

Carbon Nanomaterials Design Laboratory, Global Research Laboratory, Research Institute of Advanced Materials, and Department of Materials Science and Engineering, Seoul National University, Seoul 151-744, Korea.

WCU Hybrid Materials Program, Department of Materials Science and Engineering, Research Institute of Advanced Materials, Seoul National University, Seoul 151-744, Korea.

*Corresponding author. Tel: (+82) 2-880-8030. Fax: $(+82)$ 2-885-1748.

E-mail address: crpark@snu.ac.kr 


\section{Experimental section}

Reagents and chemicals. Zinc nitrate tetrahydrate (Merck), terephthalic acid (Aldrich), and $N, N$ '-diethylformamide (DEF; Merck) were used without purification.

Synthesis of IRMOF-1. Zinc nitrate tetrahydrate $(0.78 \mathrm{~g}, 3 \mathrm{mmol})$ and terephthalic acid $(0.17$

$\mathrm{g}, 1 \mathrm{mmol})$ were dissolved in DEF $(30 \mathrm{~mL})$ in a vial. The reaction mixture was heated in a furnace at $105{ }^{\circ} \mathrm{C}$ for $24 \mathrm{~h}$ to yield large cubic crystals of IRMOF-1. The reaction vessel was removed from the furnace and allowed to cool to room temperature.

Preparation of ZnOQDs@amorphous carbon. The prepared IRMOF-1 were transferred to a tube furnace and were heat-treated at target temperature $\left(550{ }^{\circ} \mathrm{C}\right)$ under nitrogen with a heating rate of $10{ }^{\circ} \mathrm{C} \mathrm{min}^{-1}$ to pyrolyze the surface of MOFs. After reaching the target temperature, the materials were immediately cooled to room temperature.

Characterizations. XRD was conducted using a D8 Advance (Bruker) diffractometer. Diffractograms were recorded in reflection mode using Ni-filtered $\mathrm{CuK} \alpha$ radiation $(\lambda=0.154184 \mathrm{~nm})$. PL (Shimadzu, RF-5301 PC) was carried out for the optical characterization of the obtained $\mathrm{ZnO}$ QDs. The chemical state of the products was determined by using XPS (AXIS-HSi, KRATOS). Raman spectroscopy was conducted using a RAMANplus (Nanophoton) with $532 \mathrm{~nm}$ laser to analyze the surface chemical structure of the products. Volumetric nitrogen adsorption isotherms (at $77 \mathrm{~K}$ ) up to 1 bar were measured using a Micromeritics ASAP 2020 static volumetric gas adsorption instrument. All sorption isotherms were obtained using ultrahigh purity gases (99.999\%). Prior to the sorption analysis, samples $(0.1-0.2 \mathrm{~g})$ in the analysis chamber were subject to a vacuum of $10^{-5}$ Torr at $120{ }^{\circ} \mathrm{C}$ for 12 hours. Scanning electron microscopy (SEM; JSM6700F instrument, JEOL) and 
transmission electron microscopy (TEM; Tecnai F20, FEI) were employed for microstructure analysis.

Electrochemical properties of ZnO QDs@amorphous carbon. The cycling tests were performed using coin-type half cells (2016 type) with a Li counter electrode. The working electrode consisted of the active material, super P carbon black, and a polyvinylidene fluoride binder in a weight ratio of 3:1:1. The $1 \mathrm{M} \mathrm{LiPF}_{6}$ in ethylene carbonate/diethylene carbonate $(1 / 1$ vol. \%) (Cheil Industries Inc.) was used as an electrolyte. The cyclic voltammetry of $550 \mathrm{~N}$ was recorded with a potentiostat (CHI 608C: $\mathrm{CH}$ Instrumental Inc.) for the first 4 cycles. The range of voltage was $20 \mathrm{mV}-3.0 \mathrm{~V}$ with a scan rate of $0.1 \mathrm{mV} \mathrm{s}^{-1}$. All the potentials indicated here were referred to the $\mathrm{Li} / \mathrm{Li}^{+}$electrode potential.

The galvanostatic charge/discharge tests were performed between $20 \mathrm{mV}$ and $3.0 \mathrm{~V}$ after the first discharge from the initial open-circuit voltage. The rate capability was examined from $0.1 \mathrm{C}$ to $5 \mathrm{C}$, and the cells were cycled for 20 cycles at $0.1 \mathrm{C}$ prior to varying current densities. Both commercial $\mathrm{ZnO}$ and samples other than $550 \mathrm{~N}$ are cycled only at $0.1 \mathrm{C}$ due to the poor performance at high current densities. The electrochemical impedance spectra were measured using a potentiostat $(\mathrm{CHI}$ 608C: $\mathrm{CH}$ Instrumental Inc.) after 3 cycles at $0.1 \mathrm{C}$. The frequency range was from 0.1 to $105 \mathrm{~Hz}$ with an applied voltage of $0.256 \mathrm{~V}$. 


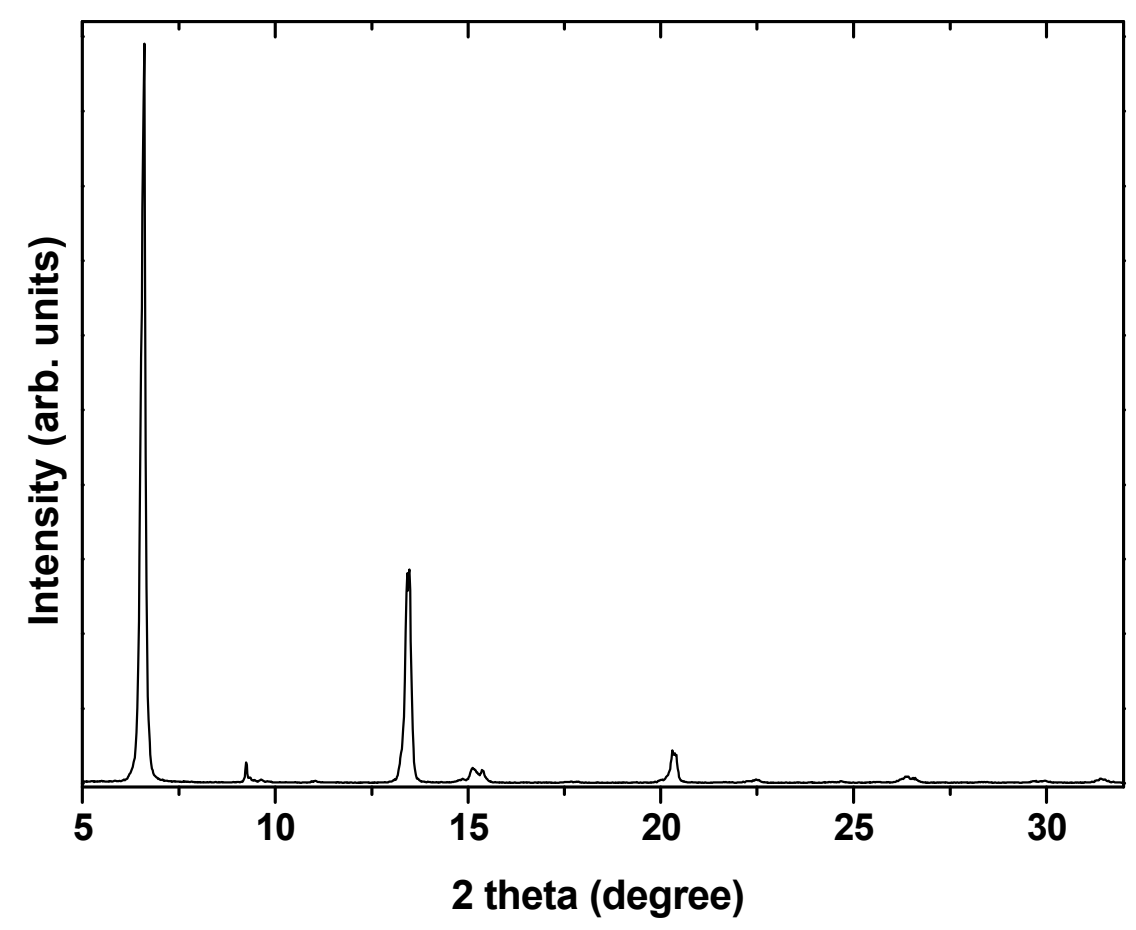

Figure S1. XRD pattern of synthesized IRMOF-1. 


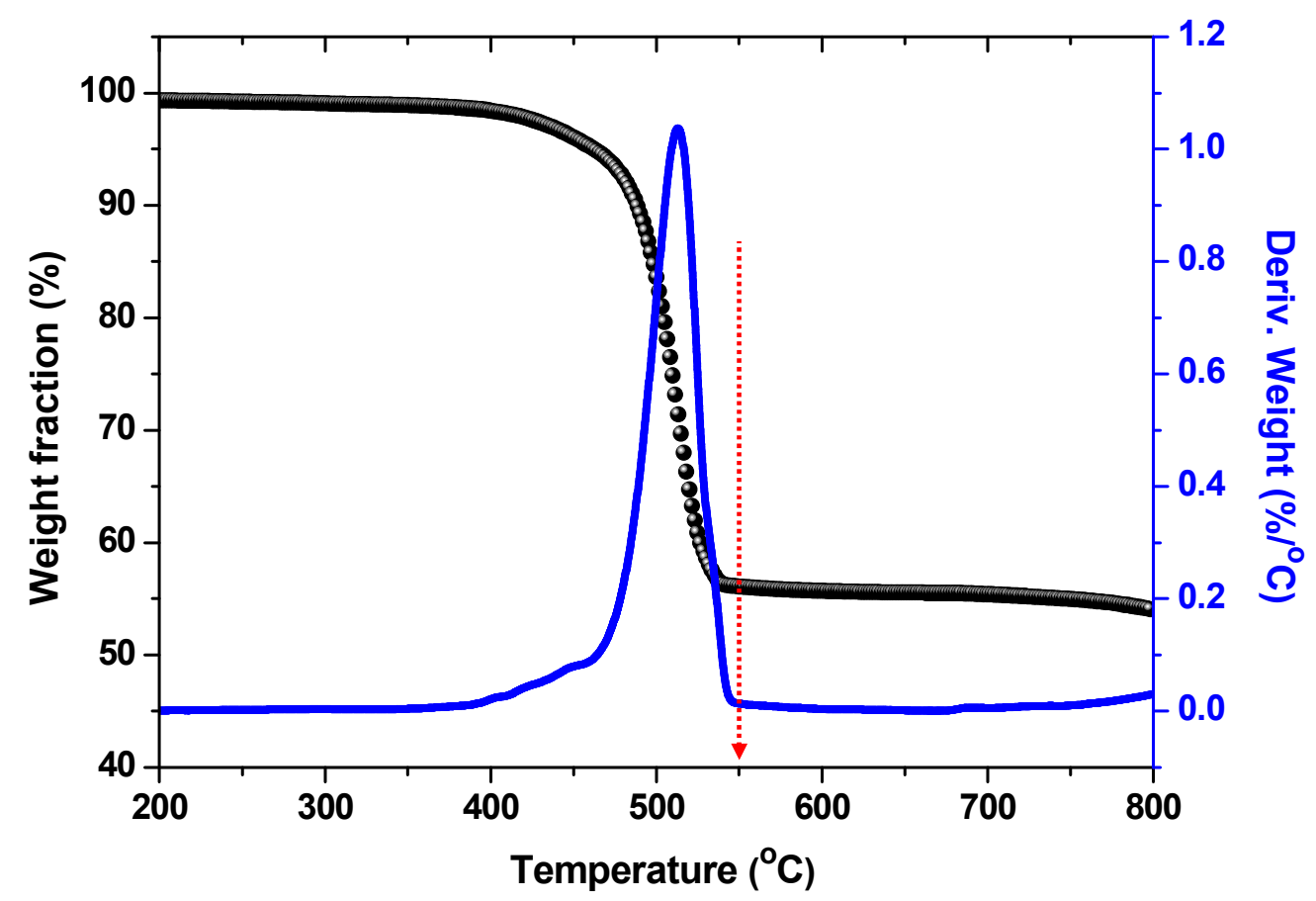

Figure S2. TGA thermogram of IRMOF-1 at nitrogen atmosphere. Red arrow indicated the target temperature $\left(550^{\circ} \mathrm{C}\right.$ : very initial state of the transformation). 


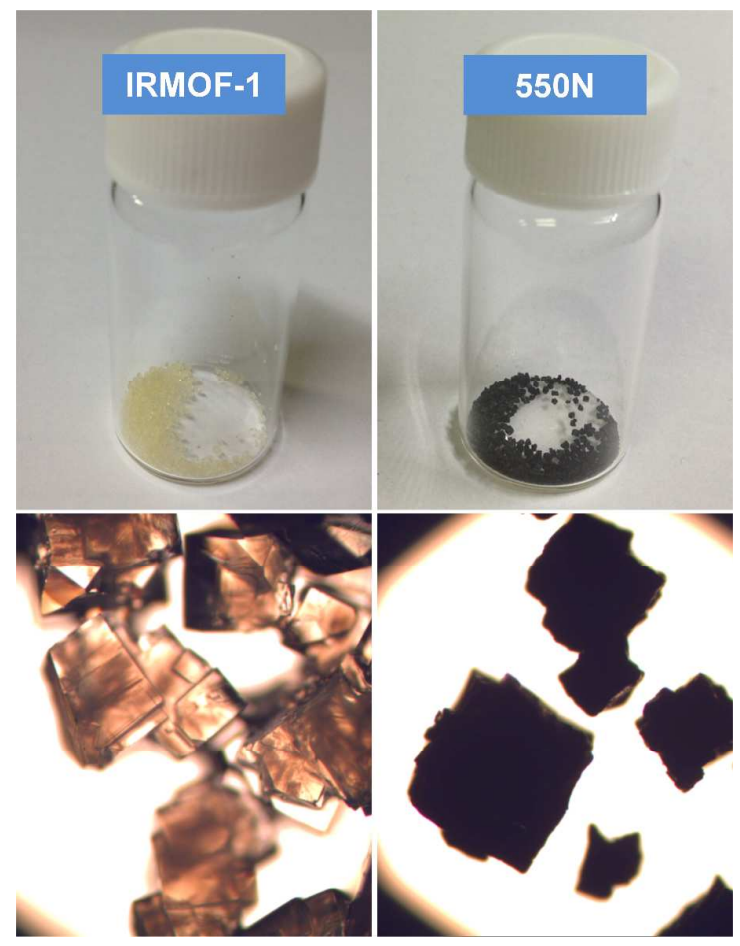

Figure S3. Photographs (top) and optical micrographs (bottom) of the IRMOF-1 and 550N. 

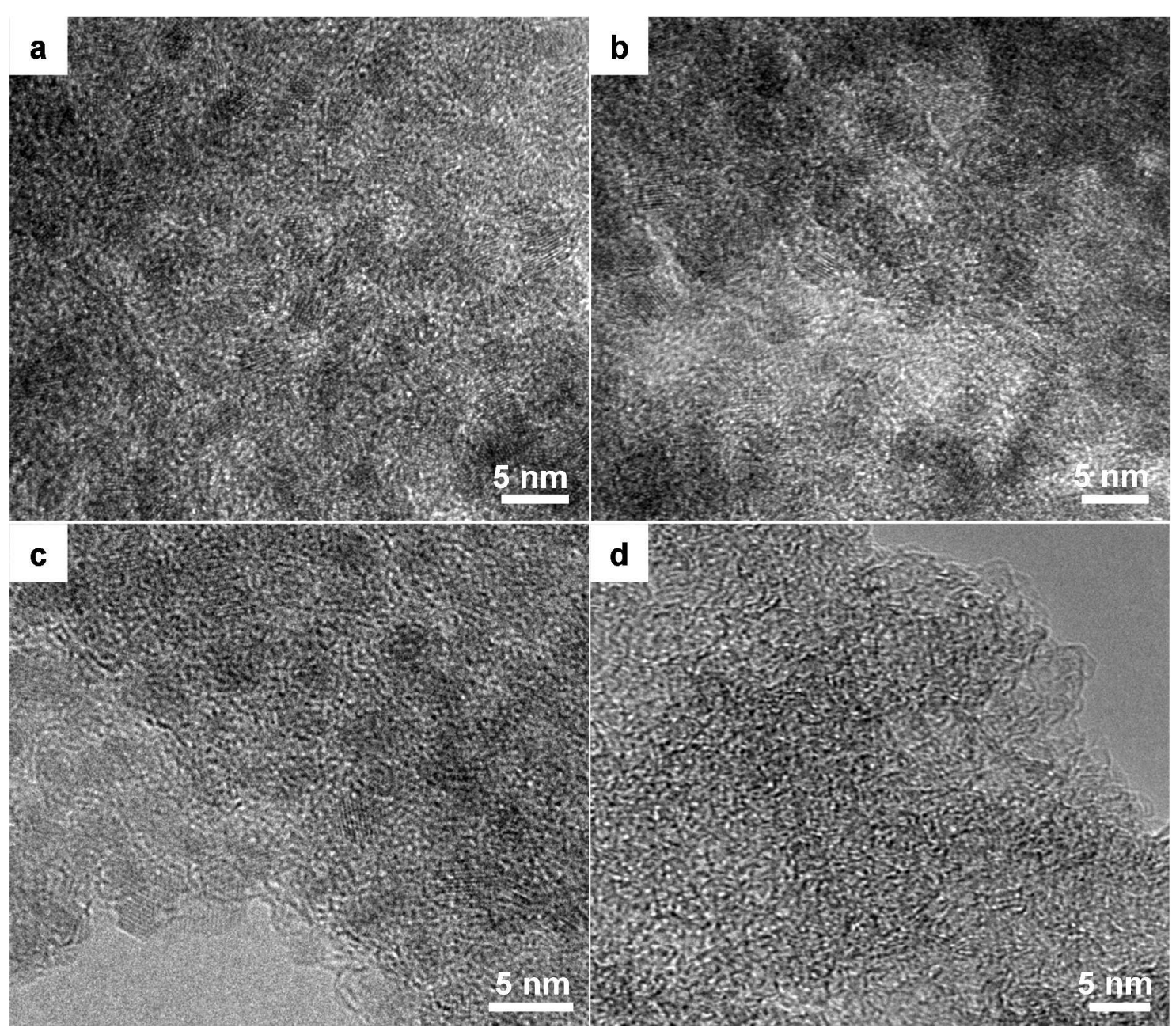

Figure S4. High-resolution TEM images of $(\mathrm{a}-\mathrm{c}) \mathrm{ZnO}$ QDs@porous carbon and (d) porous carbon, prepared by $\mathrm{HCl}$ etching of the $\mathrm{ZnO}$ QDs. 


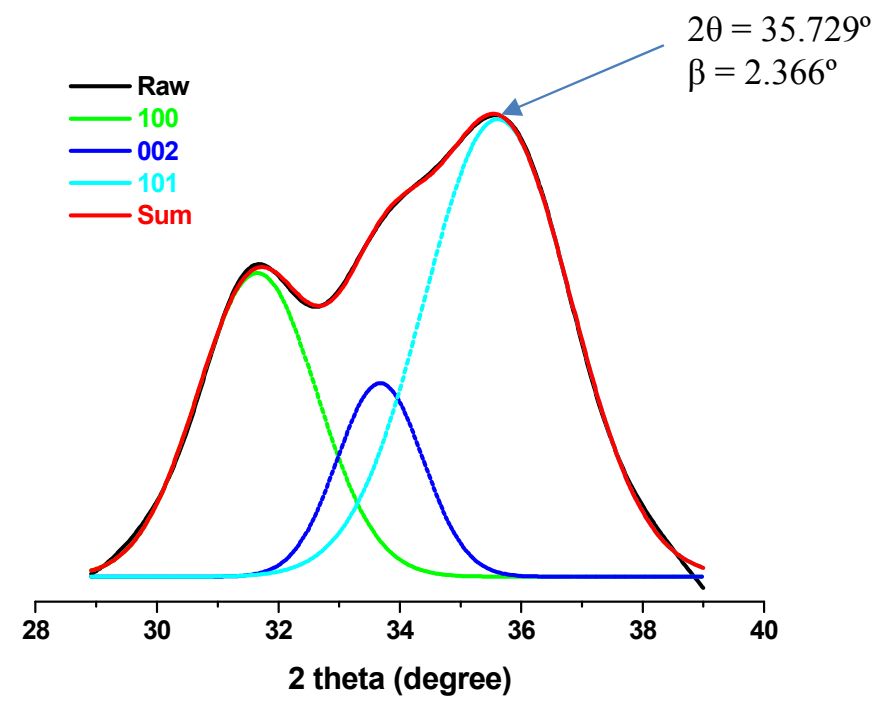

Figure S5. Application of the Scherrer equation to calculate the crystal size of the ZnO QDs.

$D=K \lambda /(\beta \cos \theta)$, where: $D=$ crystal size $(\mathrm{nm}), K=0.89$ (shape factor), $\lambda=0.15406 \mathrm{~nm}$ (wavelength of radiation used, in this case $\mathrm{Cu} \mathrm{K \alpha}$ ), $\beta=$ Diffraction line full width at halfmaximum of the peak profile on the $2 \theta$ scale in radians, and $\theta=$ Corresponding diffraction angle.

From the curve-fitted diffraction parameters, the crystalline size of the $550 \mathrm{~N}$ is about $3.5 \mathrm{~nm}$. 

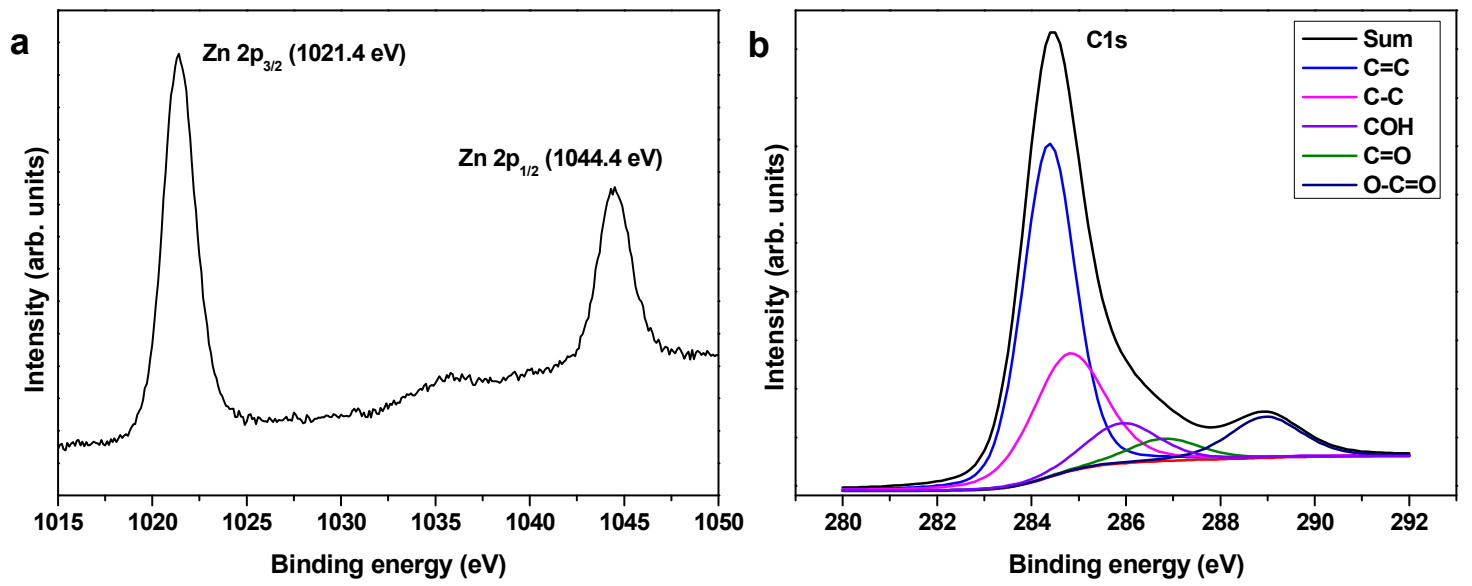

Figure S6. a) Zn 2p and b) C 1s XPS spectra of 550N.

The XPS result indicated that the obtained ZnO QDs have a high crystallinity without Zn metal (oxygen surface defect), ${ }^{\mathrm{S} 1}$ and the amorphous carbon consisted of carbon-carbon bonding and slight amount of oxygen-functionalized carbon bonding. 


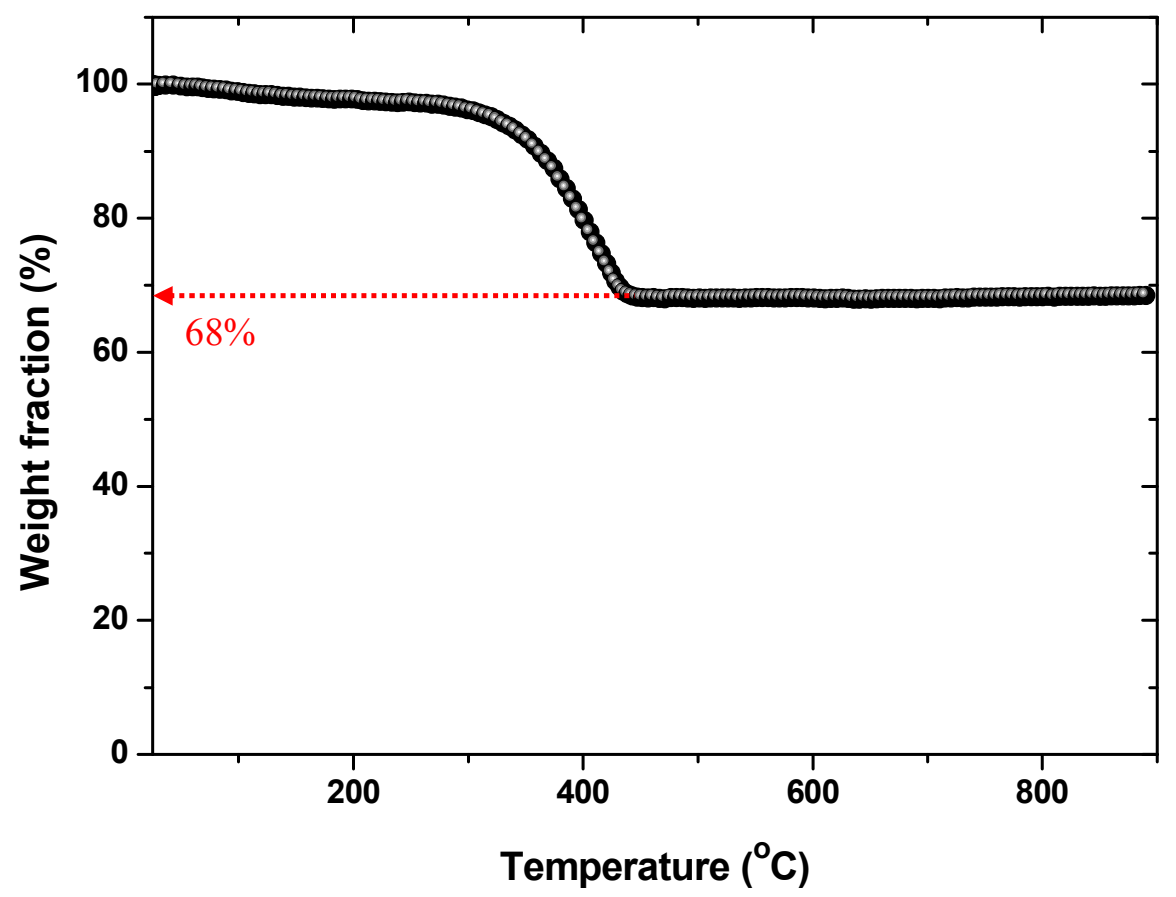

Figure S7. TGA thermogram of $550 \mathrm{~N}$ at air atmosphere. Red arrow indicated the amount of the $\mathrm{ZnO}$ in $550 \mathrm{~N}$ sample (carbon contents: $32 \mathrm{wt} \%$ ). 


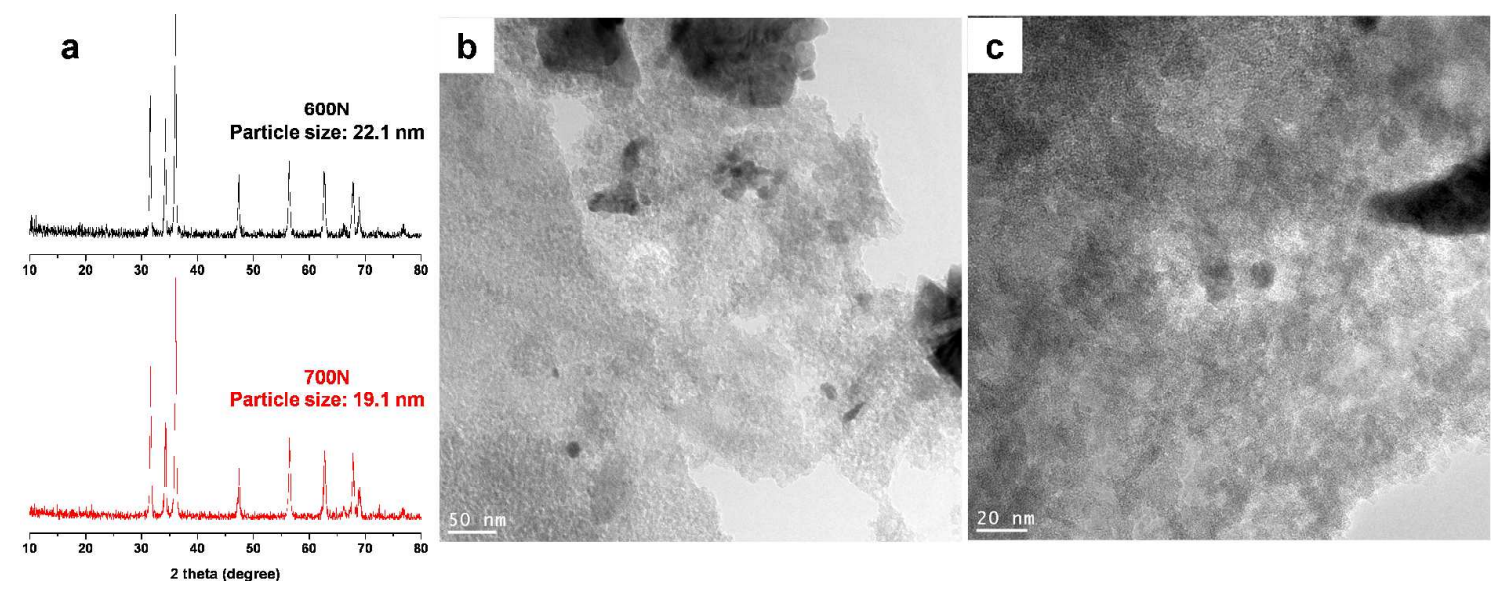

Figure S8. (a) XRD patterns and TEM images of (b) $600 \mathrm{~N}$ and (c) $700 \mathrm{~N}$. 


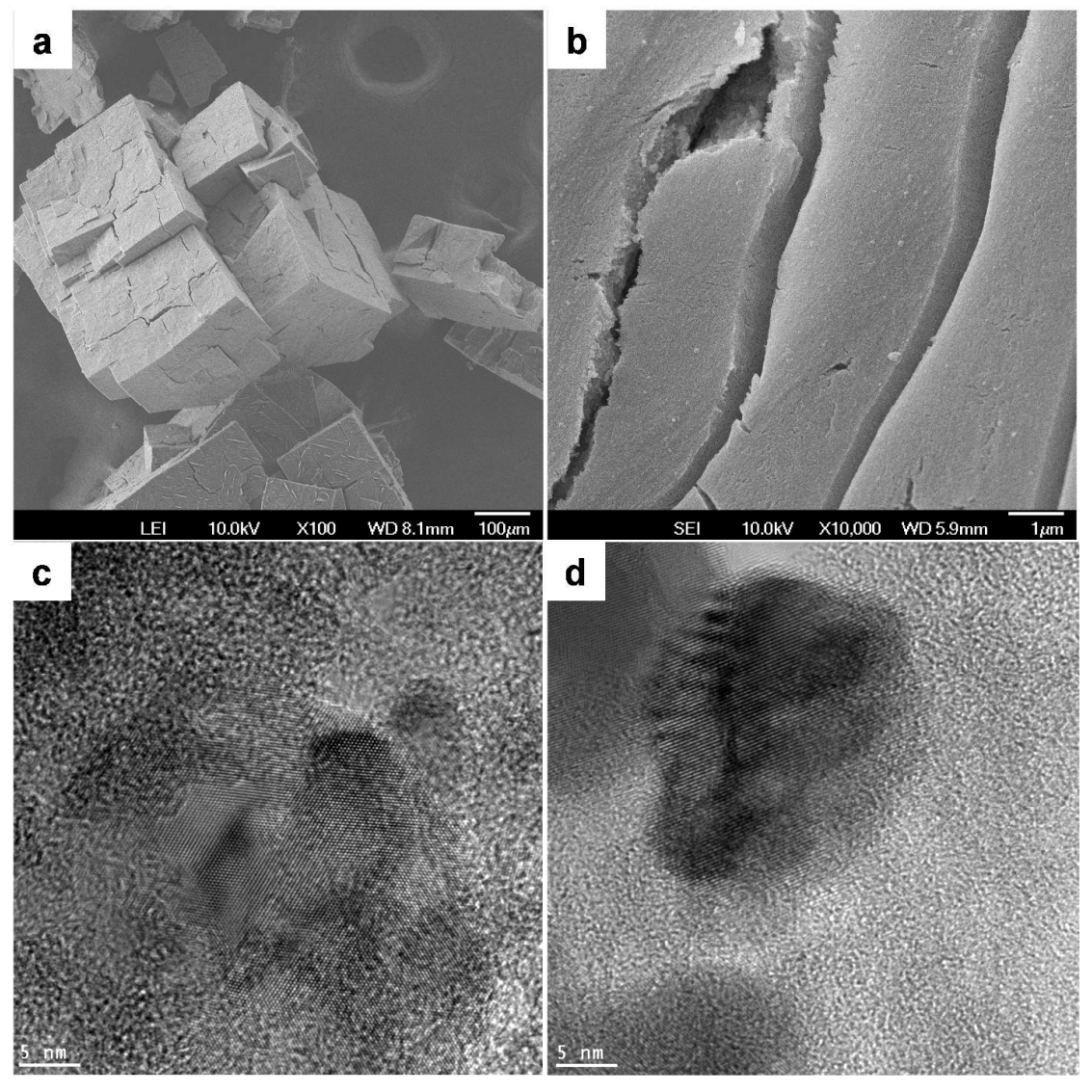

Figure S9. FE-SEM images (a, b) and TEM images (c, d) of 550N_5C $\left(5^{\circ} \mathrm{C} / \mathrm{min}\right.$ to $\left.550{ }^{\circ} \mathrm{C}\right)$ 

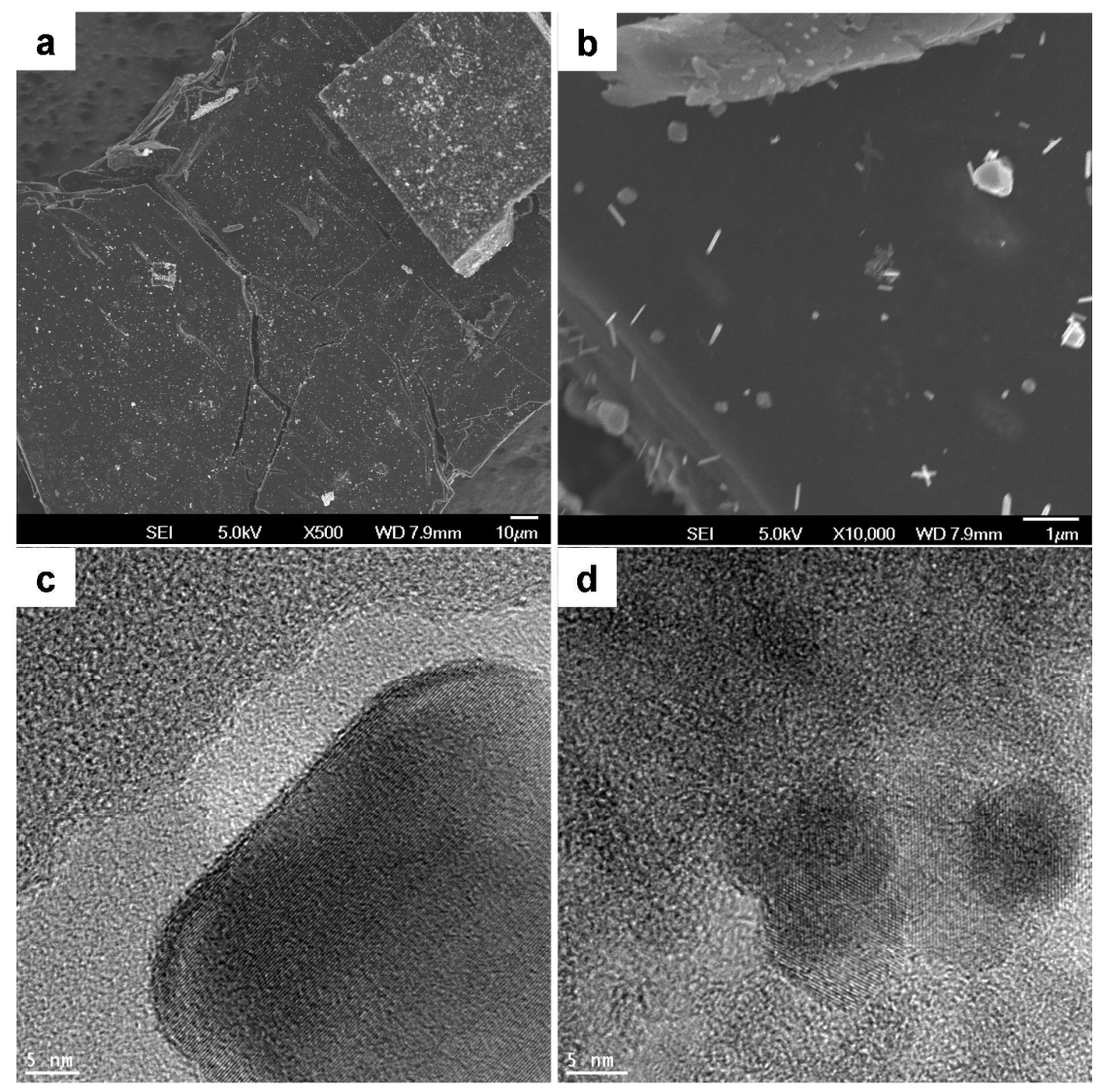

Figure S10. FE-SEM images (a, b) and TEM images (c, d) of 550N_3H $\left(10{ }^{\circ} \mathrm{C} / \mathrm{min}\right.$ to $550{ }^{\circ} \mathrm{C}$ and retaining the temperature for 3 hours) 

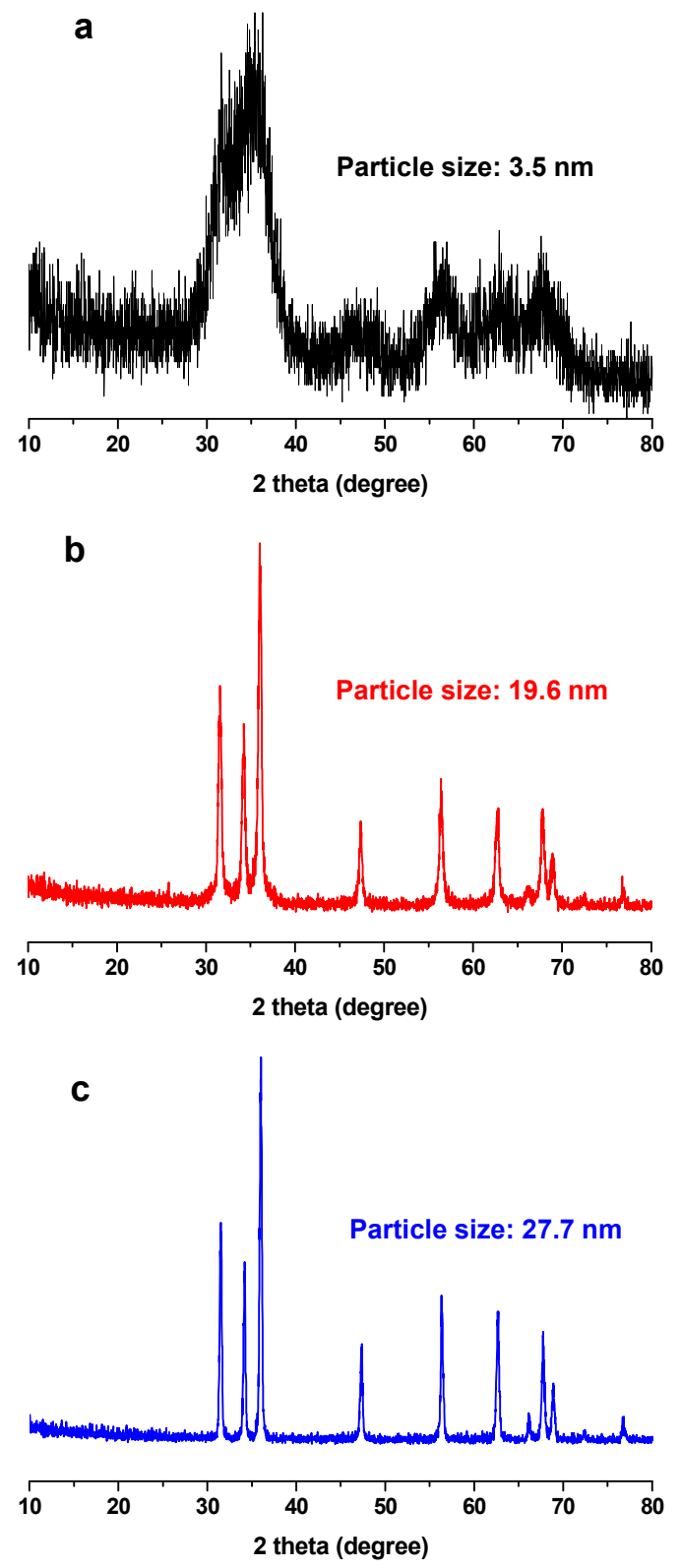

Figure S11. XRD patterns and particle sizes calculated with using Scherrer equation of (a) $550 \mathrm{~N}$, (b) $550 \mathrm{~N} \_5 \mathrm{C}$, and (c) $550 \mathrm{~N} \_3 \mathrm{H}$. 


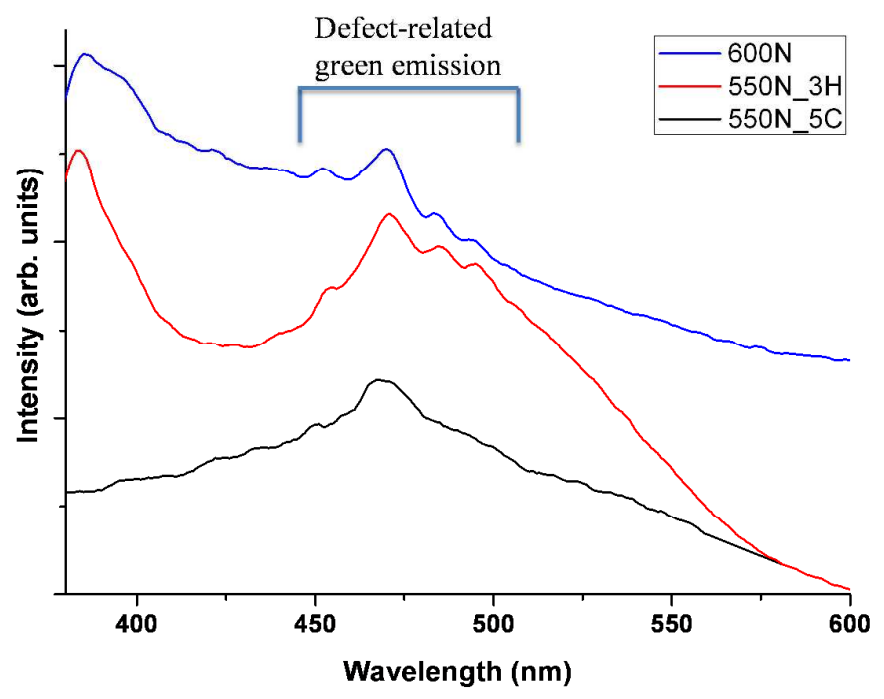

Figure S12. PL spectra of 550N_5C and 550N_3H.

PL spectra of the products synthesized at different pyrolysis conditions exhibited low-energy blue-green band emission, which strongly related with the oxygen vacancies or interstitial zinc sites. PL spectra of the products therefore manifested the reduction of $\mathrm{ZnO}$ in the presence of carbonaceous materials and, consequently, the surface defect associated with oxygen vacancies or interstitial zinc sites was generated. ${ }^{\mathrm{S} 2-4}$ 


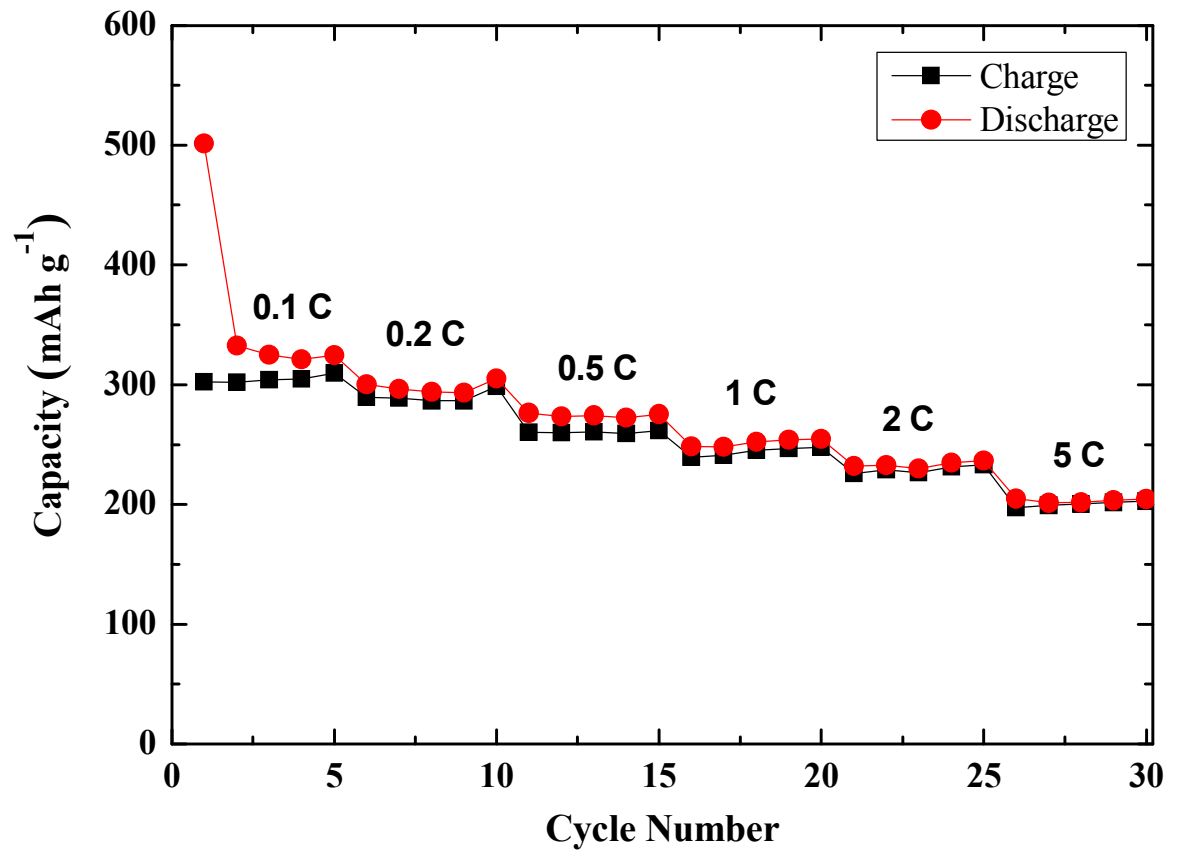

Figure S13. Cycling performance of the super P carbon black.

It should be noted that some of the reversible capacity originated from the super P carbon considering it stored lithium ion (Figure S13) and was $20 \mathrm{wt} \%$ of the whole electrode. The reversible capacity can be overestimated by about $\sim 107,97,90,83,73$, and $67 \mathrm{mAhg}^{-1}$ at 0.1 , $0.2,0.5,1,2$, and 5 C-rate, respectively $\left(1 \mathrm{C}=372 \mathrm{~mA} \mathrm{~g}^{-1}\right)$. 

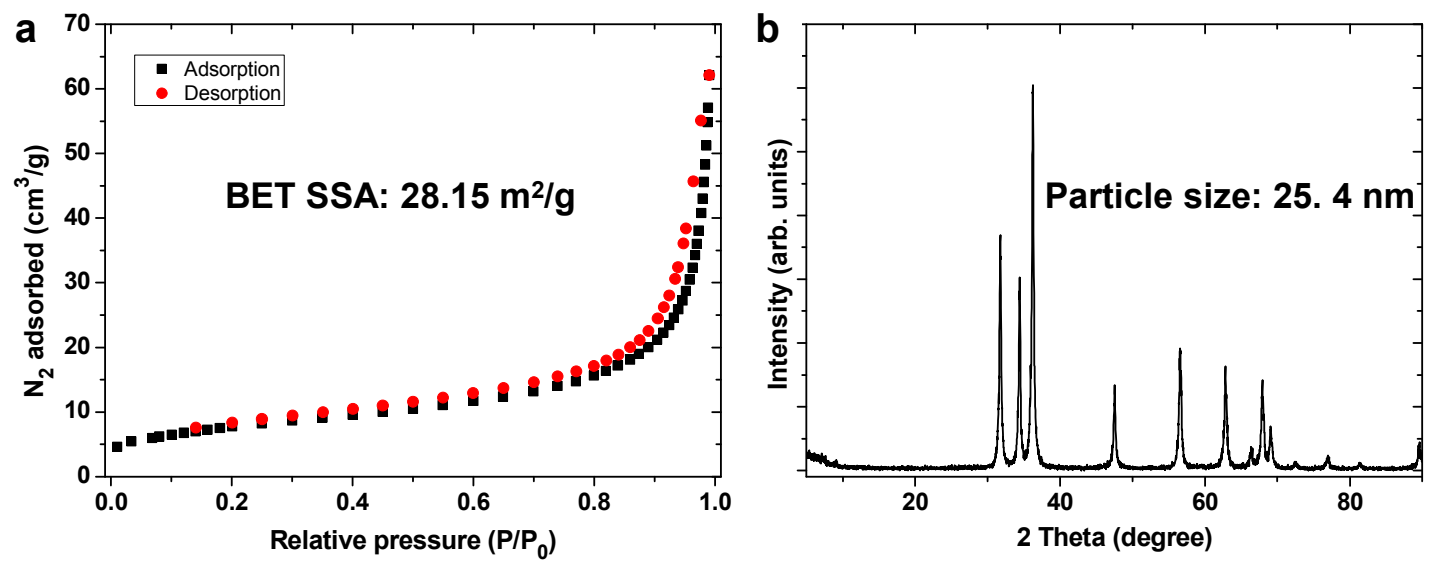

Figure S14. a) XRD pattern and b) nitrogen adsorption isotherm at $77 \mathrm{~K}$ of commercial $\mathrm{ZnO}$ particles. 


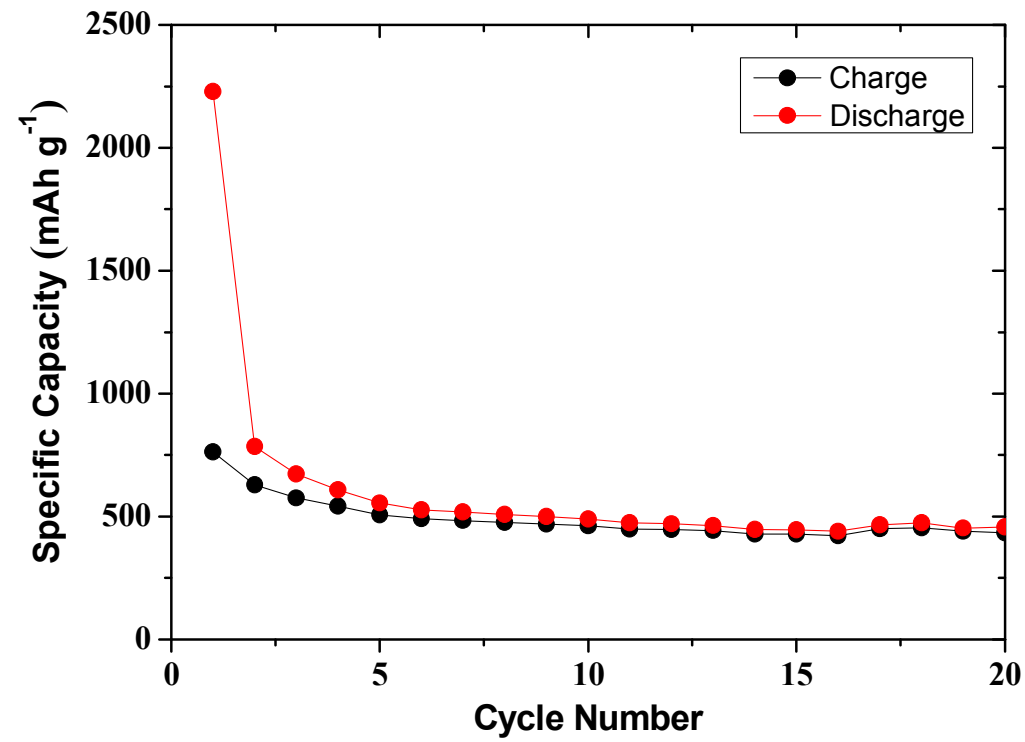

Figure S15. The cycle-life performances of amorphous carbon (removal of $\mathrm{ZnO}$ QDs from $550 \mathrm{~N}$ sample by $\mathrm{HCl}$ washing). 


\section{References}

(S1) Wang, L. S.; Xiao, M. W.; Huang, X. J.; Wu, Y. D. J. J. Hazard. Mater. 2009, 161, 49-54.

(S2) Vanheusden, K.; Warren, W. L.; Seager, C. H.; Tallant, D. R.; Voigt, J. A.; Gnade, B. E. J. Appl. Phys. 1996, 79, 7983-7990.

(S3) Liu, B.; Shioyama, H.; Akita, T.; Xu, Q. J. Am. Chem. Soc. 2008, 130, 5390-5391.

(S4) Yang, S. J.; Kim, T.; Im, J. H.; Kim, Y. S.; Lee, K.; Jung, H.; Park, C. R. Chem. Mater. 2012, 24, 464-470. 